lithium level in drinking water and district suicide mortality. The authors were careful to perform sensitivity analyses to examine the impact of extreme values on the outcome, and log-transformed many independent variables, as WLS is known to be sensitive both to extreme values and to distribution of variables. However, one most important aspect about the WLS analysis which seems not to be articulated in the paper is that in the model estimate of WLS analysis much depends on the choice of weighting variable. A different weighting would produce different estimates, in particular standard error of estimates. It is not clear what weighting variable the authors used in their analysis. Was it population size of district or variance of suicide mortality or something else? Was sensitivity analysis carried out on different weighting variables? Would the significant finding still be present if different weighting variables were used? What would be a better weight for this data-set? There seems a black box of uncertainty in interpreting the results.

Third, it is well known that ecological analysis is subject to the ecological fallacy, namely, association from the ecological model at area level may overestimate the population association that would be established by individual-level analysis. ${ }^{2}$ Although not every ecological analysis necessarily presents such drawbacks, this study has not shown justification for not having such a problem. A negative correlation between suicide standardised mortality rate (SMR) and some area poverty measures such as unemployment rate and population density were not supported by individuallevel analysis. ${ }^{3}$

Finally, since both district data on lithium concentrations and suicide mortality are available for up to 5 years for the period 2005-2009, the study could have obtained findings with more statistical power than the current findings if multilevel Poisson models for repeated measures within region were used for analysing SMR data. ${ }^{4}$ To organise data as years $(i=1-5)$ nested within district $(j=99)$, such a model will have many more datapoints (maximum 495) so that important variables such as age and gender in some type of aggregated form, such as percentage of female and percentage of old people per district, could be included in the analysis without overfitting the model. In addition, the increasing trend of suicide mortality over time and variability of the SMR between districts and over time can be disentangled in the model. Although this model still cannot provide evidence on causal relationships based on aggregated data, it can overcome some limitations in the method used in the study. The core finding of this study as currently presented cannot be supported unless further analyses by means of more advanced multilevel models also yield the same finding.

1 Platt S, Boyle P, Crombie I, Feng Z, Exeter D. The Epidemiology of Suicide in Scotland 1989-2004: An Examination of Temporal Trends and Risk Factors at National and Local Levels. Scottish Government, 2007 (http:// www.scotland.gov.uk/Publications/2007/03/01145422/0).

2 Robinson, WS. Ecological correlations and the behavior of individuals. Am Sociol Rev 1950; 15: 351-7.

3 Lin S. Unemployment and suicide: panel data analyses. Soc Sci J 2007; 43: 727-32

4 Rasbash J, Steele F, Browne WJ, Goldstein H. A User's Guide to MLwiN (Version 2.10): 117-28. Institute of Education, University of London, 2000.

Min Yang, Professor of Medical Statistics, Division of Psychiatry, School of Community Health Sciences, University of Nottingham, Nottingham NG7 2TU, UK. Email: min.yang@nottingham.ac.uk

doi: 10.1192/bjp.198.6.493a

Authors' reply: In attempting to replicate the findings of Oghami and colleagues, ${ }^{1}$ it was our aim to stay close to their methods thus allowing for comparison with our results. Using weighted least squares (WLS) regression in ecological studies is a recognised method. ${ }^{2,3}$ By incorporating previous criticism, we extended the WLS model of Oghami et al by implementing further covariates and tested for stability of the hypothesis. As stated originally, weighting by population per district (number of inhabitants per district), was chosen.

In order to clarify the uncertainty raised by Yang, we recalculated the lithium estimates $\left(R^{2}=0.38 ; \beta=-0.24\right.$; $t=-2.33 ; P=0.022$ ) from the multivariate WLS model from Table 2: (a) without log-transformation of variables and (b) with additional weighting variables. Using non-transformed covariates, the estimates for lithium levels in the multivariate model were: $\mathrm{R}^{2}=0.35 ; \beta=-0.25 ; t=-2.71 ; P=0.008$. Weighting for the variance of suicide mortality produced a similar result for lithium levels $\left(\mathrm{R}^{2}=0.41 ; \beta=-0.35 ; t=-3.40 ; P=0.001\right)$ and weighting for the variance of lithium levels even improved the estimates $\left(\mathrm{R}^{2}=0.76 ; \beta=-0.55 ; t=-7.17 ; P=2.9 \times 10^{-10}\right)$, which further supports our hypothesis.

Concerning the issue of ecological fallacy, we rephrase a part of our discussion: it is clear that our study design cannot prove cause and the results are not applicable to individual cases. Our statement that we provide conclusive evidence, that lithium concentrations in drinking water are inversely correlated with suicide rates, is far away from any ecological fallacy. It would have been unacceptable to state that drinking lithium-containing water will reduce an individual's risk for suicide. Such suggestions could only be justified after double-blind placebo-controlled randomised trials with evidence level 1 (Grade A recommendation) according to the Oxford Centre for Evidence-based Medicine (www.cebm.net). Such trials would be desirable after the presentation of our replicated ecological evidence which can be classified as level $2 c$ evidence and thus only justify a Grade B recommendation.

A recalculation of the model by means of a multilevel Poisson model with repeated measures would indeed be interesting and would further challenge the hypothesis. As previously applied by us, ${ }^{4}$ a hierarchical Bayesian model incorporating the neighbourhood structure to estimate the effects of variables on suicide mortality would be even more appropriate and will be applied in the context of a future study, which will take additional variables into account.

1 Ohgami H, Terao T, Shiotsuki I, Ishii N, Iwata N. Lithium levels in drinking water and risk of suicide. Br J Psychiatry 2009; 194: 464-5.

2 Nurminen N. Linkage Methods for Environment and Health Analysis: 1-19. Technical Guidelines. World Health Organization, 1997.

3 Morgenstern $\mathrm{H}$. Uses of ecologic analysis in epidemiologic research. Am J Public Health 1982; 72: 1336-44.

4 Kapusta ND, Posch M, Niederkrotenthaler T, Fischer-Kern M, Etzersdorfer E, Sonneck G. Availability of mental health service providers and suicide rates in Austria: a nationwide study. Psychiatr Serv 2010; 61: 1198-203.

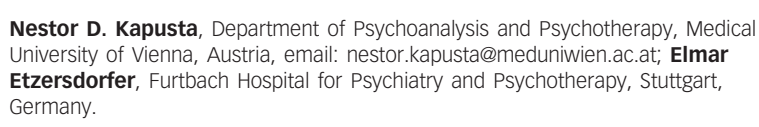

Nestor D. Kapusta, Department of Psychoanalysis and Psychotherapy, Medical University of Vienna, Austria, email: nestor.kapusta@meduniwien.ac.at; Elmar Etzersdorfer, Furtbach Hospital for Psychiatry and Psychotherapy, Stuttgart, Germany.

doi: $10.1192 /$ bjp. 198.6 .494

\section{Suicide as protest against social suffering in the Arab world}

Since ancient times there has been a difference between suicide (an act of self-destruction) and self-immolation which, although selfdestructive, has a sacrificial connotation. Self-immolation is associated with terrible physical pain (burning alive) and with the idea of courage. In modern times it has been used, among 
others, by Buddhist monks to protest against political oppression in the 1960s. It is, however, a new phenomenon in Arab Muslim societies.

As in many other religions, suicide is condemned by Islam. It is a sin which may be punished by burning in hell. The selfimmolation of the young Tunisian Mohamed Bouazizi, a street vendor, expresses both the extreme hurt associated with the harassment and humiliation that was inflicted on him after his wares had been confiscated, and the fact that there were no other ways to be heard in a country where he knew no kind of political system other than dictatorship. This individual gesture had a catalyst effect, bringing together the voices of the voiceless and provoking an unprecedented movement of rebellion and protest in Tunisia which culminated with the departure of the head of state. His gesture is now being replicated, mostly by other young men in Arab countries.

Although these events clearly belong to the social and political sphere, they also raise important issues for psychiatrists and mental health professionals. First, these events highlight the social, political and cultural dimensions of suicide as a powerful collective idiom of distress. In the Tunisian case there is a shift from an individual sinful suicide to a sacrifice which evokes martyrdom. Fire symbolises purification and self-immolation may represent the collective desire for a transformation, a rebirth out of corruption. In recent decades, it is to be noted that martyrdom has become a common way to confront oppression, felt injustice and social suffering. Usually self-destruction was a way to destroy an enemy which was defined as external. In the present case, destruction is limited to the individual and the target of the protest is the national state. This may be an indication of a fracture in the 'us and them' polarisation, which has been put forward in the War on Terror and has not only characterised mounting international tensions but has facilitated the overall projection of suffering and oppression onto external enemies.

Second, in spite of the fact that the idiom of distress put forward by these Arab youth is radically different from the usual profile of youth suicide in Western countries, these events may also be an invitation to rethink the collective dimensions of youth suicide as a protest against society. Without minimising the role of psychopathology and interpersonal factors, it may be time to revisit the collective meaning associated by youth with the decision to exit a world in which they may feel they do not always have a voice.

Imen Ben Cheikh, Psychiatry Resident R4, Sherbrooke University, Quebec, Canada. Email: imen.ben.cheikh@usherbrooke.ca; Cécile Rousseau, Professor, Division of Social and Cultural Psychiatry, McGill University, Quebec, Canada; Abdelwahed Mekki-Berrada, Professor, Anthropology Department, Laval University, Quebec, Canada

doi: 10.1192/bjp.198.6.494a

Is Faith Delusion? Why religion is good for your health [book review]. BJP, 198, 412. Second paragraph, sentence 19 should read: 'To quote Eagleton again, "The message of the New Testament is that if you don't love you are dead, and if you do, they will kill you"'.

Anandamide elevation in cerebrospinal fluid in initial prodromal states of psychosis. BJP, 194, 371-372. The eighth author's affiliation should read: Daniele Piomelli, DPharm, PhD, Departments of Pharmacology and Biological Chemistry, University of Califomia, Irvine, Irvine, California, and Unit of Drug Discovery and Development, Italian Institute of Technology, Genoa, Italy.

doi: 10.1192/bjp.198.6.495 